\title{
Ophthalmic Manifestations of Hodgkin Lymphoma: A Review
}

\author{
Juan Valenzuela ${ }^{a}$ Jose J. Echegaray ${ }^{b}$ Emilio Dodds ${ }^{c}$ Shree K. Kurup ${ }^{b}$ \\ Careen Lowder $^{d}$ Sarah L. Ondrejka ${ }^{e}$ Arun D. Singh ${ }^{d}$ \\ aDepartment of Retina and Ophthalmic Oncology, Consultores Oftalmológicos, Buenos Aires, Argentina; ${ }^{b}$ University \\ Hospitals Eye Institute, Case Western Reserve University, Cleveland, OH, USA; 'Department of Uveitis, Consultores \\ Oftalmologicos, Buenos Aires, Argentina; ${ }^{\mathrm{d}}$ Cole Eye Institute, Cleveland Clinic, Cleveland, OH, USA; e Pathology and \\ Laboratory Medicine Institute, Cleveland Clinic, Cleveland, OH, USA
}

\section{Keywords}

Hodgkin lymphoma · Uvea · Iris · Ciliary body · Choroid .

Granulomatous uveitis · Infiltration · Optic nerve infiltration ·

Paraneoplastic retinopathy

\begin{abstract}
Background: Hodgkin lymphoma $(\mathrm{HL})$ is a hematopoietic neoplasm characterized by cancerous Reed-Sternberg cells. In contrast to ophthalmic manifestations by non-HL that are well recognized, there is paucity of the literature as it relates to ophthalmic manifestation by HL. We performed a comprehensive review of published studies (case reports and small case series) to characterize the ophthalmic manifestations of HL. Summary: Thirty patients were identified with ophthalmic manifestation of HL. Thirteen (43\%) were male, and 14 (46\%) were female (in 3 cases, sex was not specified). The median age at ophthalmic presentation was 27 years. Diagnosis of HL was made after ophthalmic manifestation in $10(33 \%)$ cases, whereas 11 (36\%) cases had a prior diagnosis of HL. Ophthalmic manifestations can be classified into 3 main groups; direct infiltration, inflammatory reaction, and paraneoplastic process. Seven cases had infiltration of the optic nerve. Uveal inflammatory reaction was reported in 21 cases. The presence of intraocular Reed-Sternberg cells had
\end{abstract}

been confirmed in 1 case with granulomatous uveitis. Conjunctival and corneal reaction was seen in 3 cases. HL was in stage 2 or higher, with only 1 case with stage $1 \mathrm{~A}$ ( 12 cases $\mathrm{HL}$ stage not specified). Seven cases (22\%) died of HD, all were diagnosed with advanced lymphoma, and none was treated with chemotherapy. Key Message: Ocular involvement in $\mathrm{HL}$ is extremely rare. A few cases of histopathologically confirmed optic nerve/tract infiltration are within the spectrum of CNS involvement by HL. Inflammatory uveitis is the most common ophthalmic association of HL. In the presence of prior known diagnosis of $\mathrm{HL}$, restaging should be considered to exclude recurrence. Toxicity or adverse reaction to drugs used to treat $\mathrm{HL}$ may also contribute to ophthalmic involvement.

(c) 2021 S. Karger AG, Basel

\section{Introduction}

Classic Hodgkin lymphoma (HL) is a hematopoietic neoplasm characterized by a minority of neoplastic Hodgkin/Reed-Sternberg cells admixed in an inflammatory cell infiltrate that comprises the majority of cellularity. Hodgkin/Reed-Sternberg cells are classically bi- or multinucleated giant cells with prominent nucleoli but can
Correspondence to:

Arun D. Singh, singha@ccf.org 

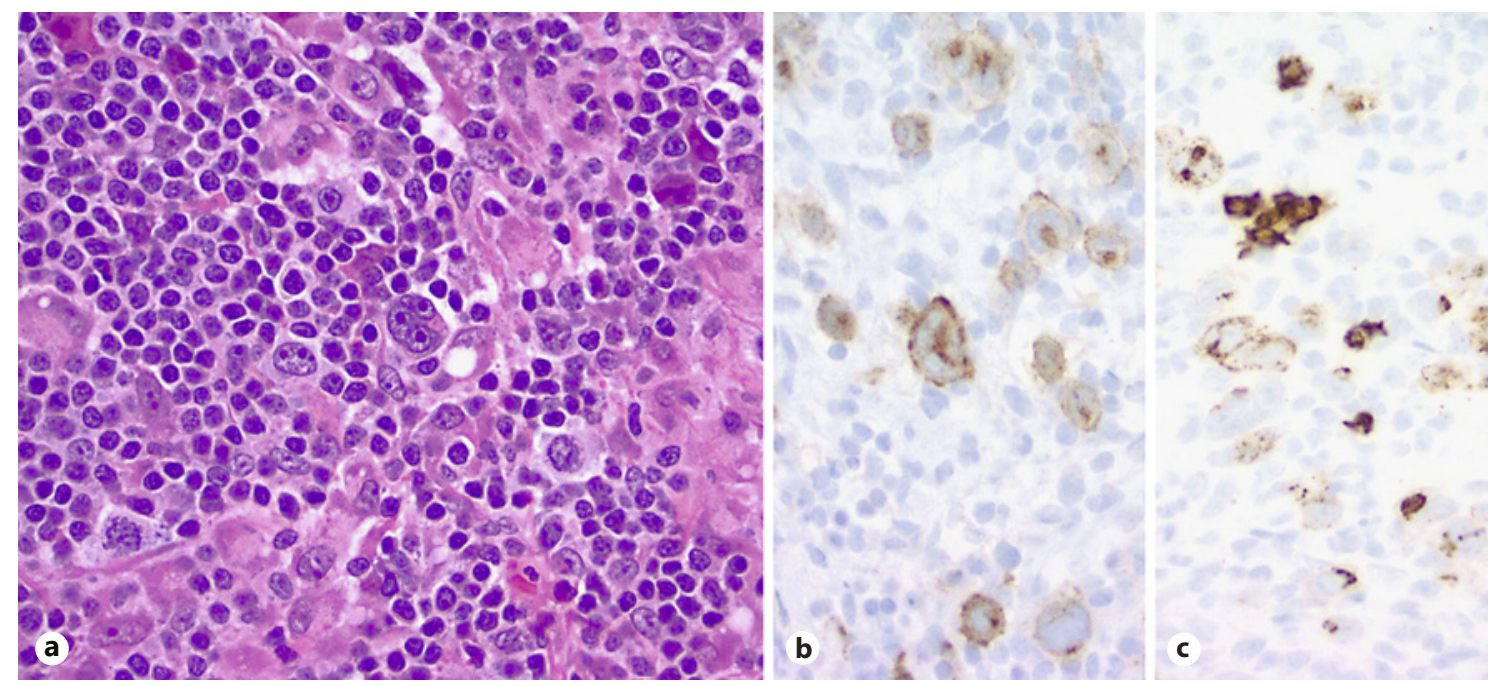

Fig. 1. Photomicrograph of classic HL with neoplastic Reed-Sternberg cells and an inflammatory background (a, $\times 500)$. The Reed-Sternberg cells are positive for CD30 (b, ×500) and CD15 (c, ×500). HL, Hodgkin lymphoma.

take the form of transformed, mono-lobated Hodgkin variants or lacunar cell variants. There are 4 subtypes of classic HL recognized by the WHO classification, according to the growth pattern, type of fibrosis, and inflammatory cells present. These include nodular sclerosis, mixed cellularity, lymphocyte-rich, and lymphocyte-depleted. The immunophenotype of Hodgkin/Reed-Sternberg cells is consistent and reflects that of dysfunctional immunoblasts; the cells are positive for CD30, PAX5 (weak), CD15, fascin, and +/- OCT2, and/or BOB.1 and negative for CD45 (Fig. 1) [1-3].

Most cases of classic HL when studied by single cell analysis demonstrate clonally rearranged, somatically mutated immunoglobulin genes, indicating a derivation from germinal center B cells [4]. The intense inflammatory response typical of classic HL underlies some of the implicated immunological pathways including activation of the NF-kappa B pathway and the JAK-STAT pathway [5]. The pathogenesis of classic HL is unresolved, though a subset of cases implicate the EBV virus [1]. However, given the differences in epidemiology, clinical presentation, and histological features in each of the 4 subtypes, there may be differences in the underlying biology and pathogenesis within this disease category.

Signs and symptoms include painless, swollen lymph nodes and an enlarged spleen. Systemic symptoms are reported in $25 \%$ of patients [6]. Fever, drenching night sweats, and loss of $>10 \%$ of bodyweight over 6 months are termed B symptoms and have prognostic importance. Diagnosis of $\mathrm{HL}$ is confirmed histopathologically and con- trast enhanced CT of the neck, chest, abdomen, and pelvis should be done for staging. The gold-standard current treatment is 4 cycles of Adriamycin-bleomycin-vinblastine-dacarbazine (doxorubicin, bleomycin, vinblastine, and dacarbazine) followed by 36 Gy involved-field radiotherapy [7]. Overall prognosis is good with probability of long-term survival beyond 3-4 years from treatment being similar to that of the normal population [8].

Ophthalmic involvement by HL is infrequent with affection limited to cornea, optic nerve, and uvea. To contrast well-recognized ophthalmic manifestations by nonHL, we performed a comprehensive review of the literature.

\section{Review of Literature}

We searched PubMed for articles published in English between January 1943 and October 2019 for the term "Hodgkin's" and the related terms "uveal," "ocular," and "ophthalmic" or "eye." For foreign language publications, only abstracts were reviewed. References cited within the relevant articles were also searched. We could identify only 30 patients with ophthalmic manifestations of HL. The data were extracted and collated under categories of general demographics and ophthalmic manifestations. Critical review of the case histories led us to classify the ophthalmic manifestations not only by tissue/layer involved but also into 4 pathophysiological groups of direct infiltration, inflammatory reaction, paraneoplastic, and 
Table 1. HL: optic nerve neoplastic infiltration

\begin{tabular}{|c|c|c|c|c|c|c|}
\hline Author & $\begin{array}{l}\text { Age, } \\
\text { sex }\end{array}$ & Eye & VA & Signs & Biopsy & $\begin{array}{l}\text { Diagnosis } \\
\text { of } \mathrm{HL}\end{array}$ \\
\hline Kraus [30] & $30, M$ & $\mathrm{OU}$ & OD: LP OS: $10 / 200$ & Neuroretinitis OU & $\begin{array}{l}\text { Lymph node } \\
\text { Nodular sclerosis HD }\end{array}$ & Prior \\
\hline Litvak et al. [9] & $56, \mathrm{M}$ & $\mathrm{OU}$ & OD: NLP OS: CF & $\begin{array}{l}\text { Optic disk edema with vascular and } \\
\text { inflammatory changes of the retina }\end{array}$ & $\begin{array}{l}\text { Autopsy: neoplastic infiltration of the optic } \\
\text { nerve and chiasm }\end{array}$ & Prior \\
\hline Miller and Iliff [10] & $43, M$ & $\mathrm{OU}$ & OD: $20 / 15$ OS: NLP & Unremarkable & $\begin{array}{l}\text { Autopsy: neoplastic infiltration of the optic } \\
\text { nerve }\end{array}$ & Prior \\
\hline Christmas [31] & & & & & 3 cases of optic nerve infiltration & \\
\hline Siatkowski et al. [11] & $21, M$ & $\mathrm{OU}$ & OD: 20/20 OS: CF & $\begin{array}{l}\text { Optic disk edema (OS) with } \\
\text { surrounding hemorrhages }\end{array}$ & $\begin{array}{l}\text { Lymph node } \\
\text { Nodular sclerosis HD }\end{array}$ & Prior \\
\hline
\end{tabular}

$\mathrm{OD}$, right eye; OS, left eye; $\mathrm{M}$, male; $\mathrm{HL}$, Hodgkin lymphoma.

Table 2. HL: corneal and conjunctival manifestations

\begin{tabular}{lllllll}
\hline Author & $\begin{array}{l}\text { Age, } \\
\text { sex }\end{array}$ & Eye & $\begin{array}{l}\text { Initial } \\
\text { VA }\end{array}$ & Signs & Initial diagnosis & Biopsy \\
\hline Matteucci [15] & $27, \mathrm{~F}$ & OU & $20 / 30$ & $\begin{array}{l}\text { Superficial corneal infiltration } \\
\text { HL }\end{array}$ & N/A & Biopsy of lymph node \\
\hline Barkana et al. [16] & $19, \mathrm{~F}$ & OS & $20 / 40$ & $\begin{array}{l}\text { Clear gelatinous superior limbal } \\
\text { nodules with subepithelial } \\
\text { corneal infiltrates }\end{array}$ & Keratoconjunctivitis & $\begin{array}{l}\text { Conjunctival biopsy: Noncaseating } \\
\text { granuloma. HL diagnosis after lymph } \\
\text { node biopsy }\end{array}$ \\
\hline Thakker et al. [17] & $20, \mathrm{~F}$ & OU & $20 / 20$ & $\begin{array}{l}\text { Inferior conjunctival and } \\
\text { episcleral nodules }\end{array}$ & $\begin{array}{l}\text { Paraneoplastic } \\
\text { scleritis }\end{array}$ & $\begin{array}{l}\text { Episcleral biopsy: Necrotizing } \\
\text { granuloma with perivascular } \\
\text { inflammation. HL diagnosis by lymph } \\
\text { node biopsy }\end{array}$ \\
\hline
\end{tabular}

OU, both eyes; OS, left eye; F, female; N/A, not applicable; HL, Hodgkin lymphoma.

toxic (drug-induced), illustrated by the cases managed by the authors.

\section{Clinical Features}

Of the reported cases, 13 (43\%) were male and 14 ( $46 \%$ ) were female (in 3 cases sex was not specified). The median age at ophthalmic presentation was 27 years. The diagnosis of HL was made after ophthalmic manifestation in $10(33 \%)$ cases, whereas $11(36 \%)$ cases had a prior diagnosis of HL. On 3 of the cases that had a prior diagnosis and treatment for HL, recurrence was diagnosed after affection of the eye. In 9 cases, the temporal relationship was not specified. The average delay in diagnosis was of 8 months (range 1-24 months). HL was in stage 2 or higher with only 1 case with stage 1A (12 cases HL stage not specified). Seven cases (22\%) died of $\mathrm{HD}$, all were diagnosed with advanced lymphoma, and none was treated with chemotherapy.

Ophthalmic Manifestations of Hodgkin Lymphoma
Ophthalmic Manifestations: Direct Infiltration Optic Nerve

All 7 cases diagnosed with optic nerve infiltration had advanced HL (stage 3B). In 3 cases, detailed information about the ophthalmic signs and symptoms was not given. The remaining 4 cases presented with bilateral diminished visual acuity or visual field and showed a congestive swollen disc. One case presented by Miller and Iliff [9] showed an unremarkable ophthalmoscopy, and infiltration of the optic nerve was confirmed at autopsy. Two cases died of $\mathrm{HD}$, and on autopsy, infiltration of the optic nerve by characteristic Reed-Sternberg cells was confirmed. One case was treated with radiotherapy, one with corticosteroids, and in the other 5 cases, treatment was not specified (Table 1) [9-11]. Such cases can be considered within the spectrum of CNS involvement by HL. No such cases have been reported in the last 30 years, which correlates with reducing incidence of CNS involvement in HL $[12,13]$. 
Fig. 2. A 52-year-old man with a 7-year history of refractory, stage IVB, nodular sclerosis type, and HL was evaluated for blurred vision and floaters in the left eye of a 4-week duration. The past medical history was remarkable for a relapsing course of HL involving perihilar, liver, and groin lymphadenopathy. The treatment regimen had included several chemotherapeutic protocols, such as ABVD, ICE, nivolumab, and other experimental drugs. Most recently, he received 12 cycles of pembrolizumab therapy. An interval PET/CT scan suggested improvement in prior hypermetabolic lesions but was suspicious to have new activity in the liver and spleen. Two months prior to presentation, pembrolizumab had been discontinued due to acute kidney injury. On presentation, BCVA was 20/20 OD and 20/70 OS. Right eye exam was normal except $1+$ cells in the anterior chamber and $0.5+$ anterior vitreous cells (a) with $2+$ cells in the anterior chamber and $1+$ anterior vitreous cells in the left eye (b). Notably, there was absence of disc swelling, pallor, and vessel sheathing in both eyes on examination and by fluorescein angiography $(\mathbf{c}, \mathbf{d})$. OCT was normal in the right eye (e) but showed cystoid macular edema and mild subfoveal fluid in the left eye (f). ABVD, adriamycin-bleomycin-vinblastine-dacarbazine; ICE, ifosfamide-carboplatin-etoposide; BCVA, best corrected visual acuity; HL, Hodgkin lymphoma; OD, right eye; OS, left eye.
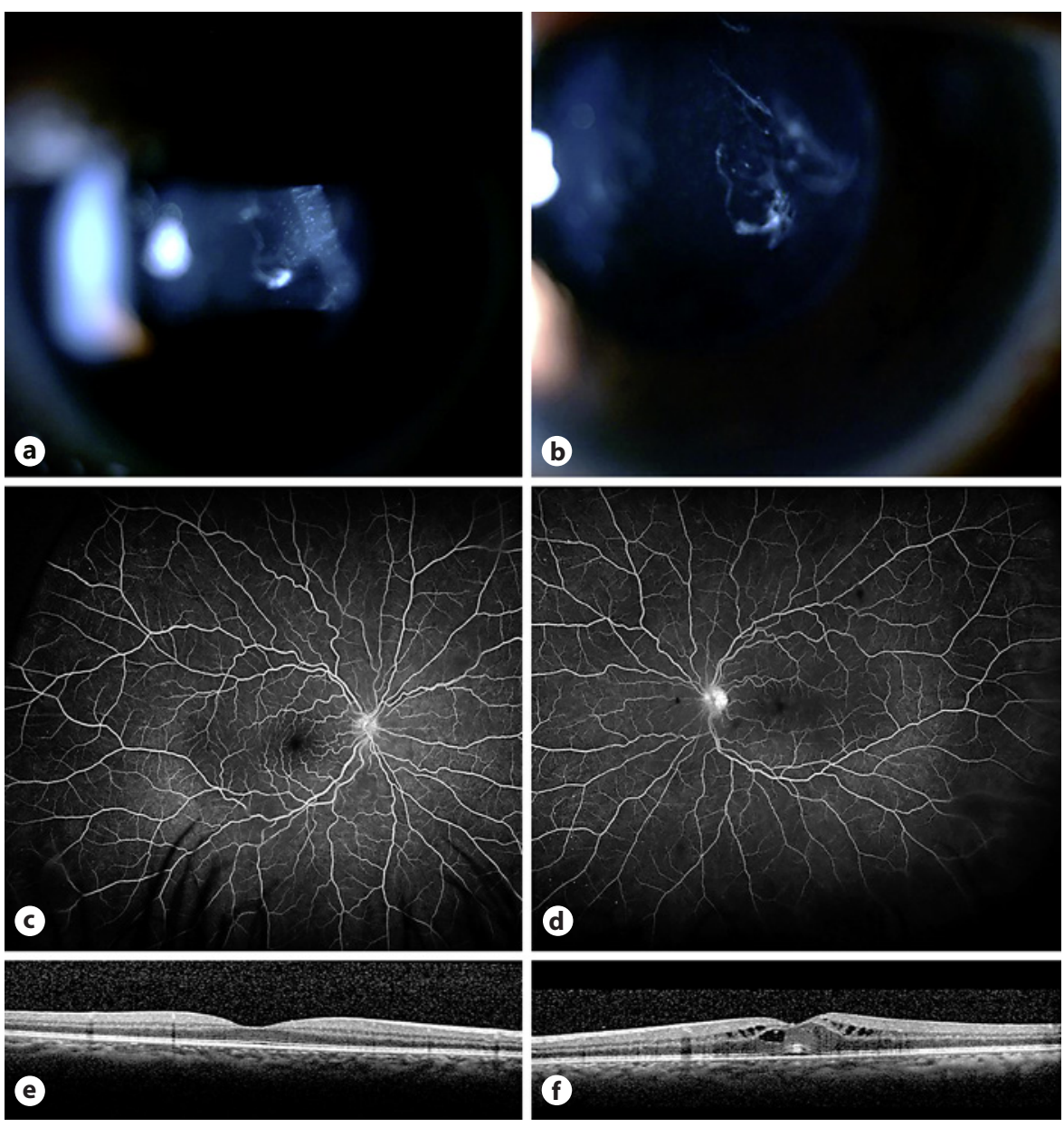

\section{Vitreoretinal}

To our knowledge, there is only one case reported in the literature with intraocular invasion by Reed-Sternberg cells. In 1961, Primbs et al. [14] reported a 73-yearold patient, with an initial diagnosis of granulomatous uveitis. The patient consulted for decreased visual acuity in both eyes. On biomicroscopy, a granulomatous anterior uveitis with mutton fat keratic precipitates, flare, posterior synechia, Koeppe iris nodules, and hazy vitreous were observed. Laboratory tests for uveitis revealed 13\% of eosinophilia, erythrocyte sedimentation rate of $26 \mathrm{~mm}$, and a negative purified protein derivative. A year and a half later, the patient developed an area of painless submandibular swelling that was diagnosed as HL and treated only with radiation therapy. Two months later, the patient died due to diffuse lymphoma invading multiples organs like the lung, brain, heart, lymph nodes, and spleen. Autopsy revealed typical Reed-Stenberg cells in the anterior chamber and in the trabecular meshwork, but there was no mention of neoplastic cells in the choroid or retina.

\section{Ophthalmic Manifestations: Inflammation \\ Cornea and Conjunctiva}

Three cases were reported with corneal or conjunctival involvement. Two had bilateral disease, and 1 case by Barkana et al. [15] had lesions only on the left eye. Two cases described multiple nodular lesions in the sclera and irregular infiltration of the cornea. Biopsy of the nodular scleral lesions disclosed necrotizing granulomas in both cases. HL diagnosis was made after lymph node biopsy, and the patients were treated with radiotherapy or chemotherapy with good outcomes (Table 2) [15-17]. 

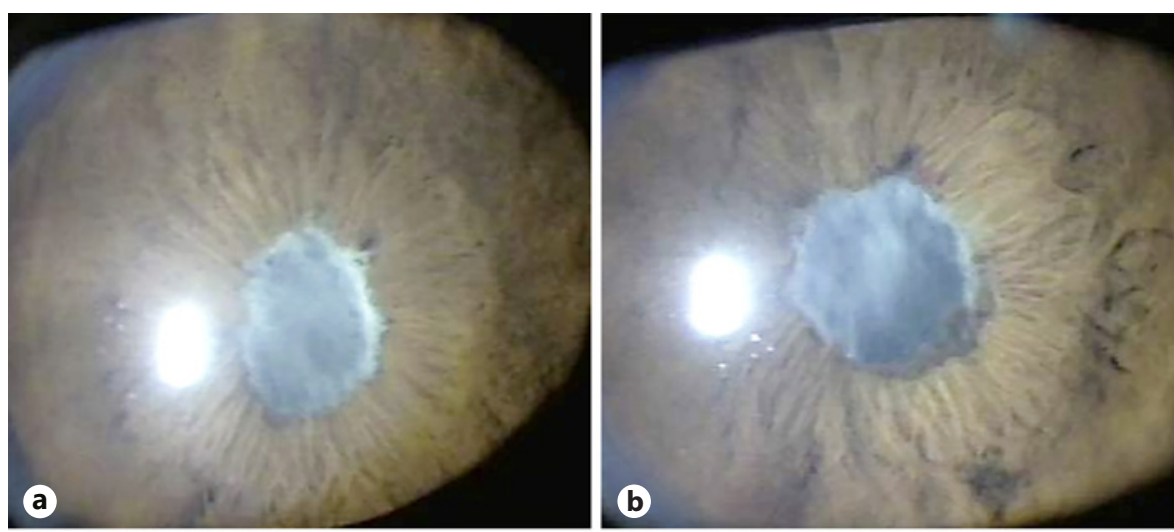

Fig. 3. A 36-year-old man was referred for unresponsive bilateral uveitis of 1-year duration. He had been treated with oral corticosteroids for a month and also for toxoplasmosis without response. Past history was relevant for HD treated with chemotherapy with complete resolution 2 years prior. On examination, the visual acuity was NLP OD and LP OS with IOP of $6 \mathrm{~mm}$ $\mathrm{Hg}$, both eyes. Anterior segment examination showed 3 + flare, posterior synechiae, and dense cataract, both eyes (a, b). Ophthalmoscopy was not possible in right eye. Total exudative retinal detachment (c) with yellowish retinal infiltration (d, perivascular) was present in the left eye. Pars plana vitrectomy, lensectomy, membrane removal, retinal biopsy (e), and internal silicone oil tamponade was performed. Histopathology revealed retinal granulomatous inflammation consisting of epithelioid cells and multinucleated cells with lymphocytes in the periphery $(\mathbf{f}, \mathrm{HE}, \times 100)$. On systemic evaluation, a new lymph node biopsy suggestive of relapse of the HD was identified that required chemotherapy. $\mathrm{OD}$, right eye; OS, left eye.
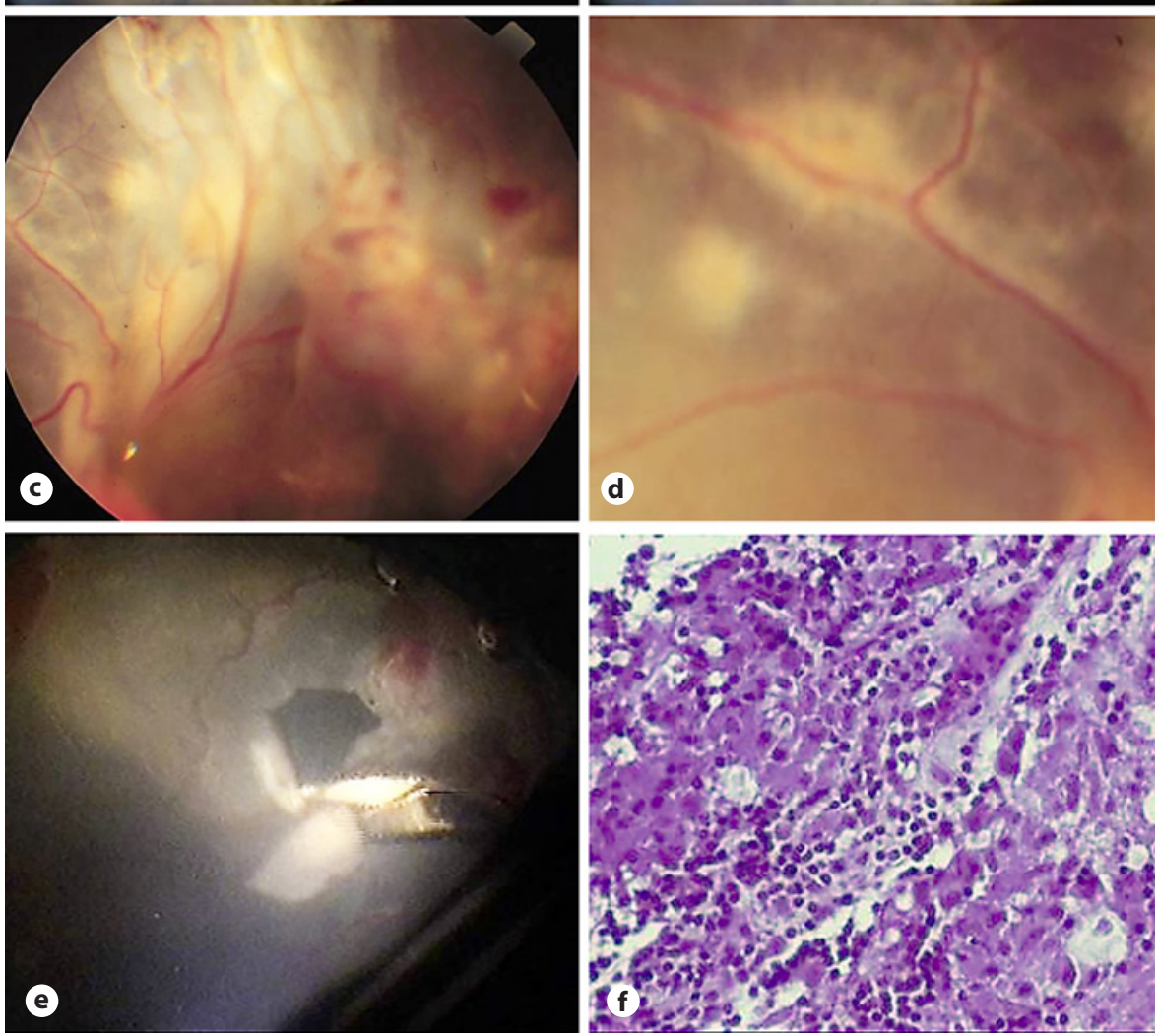

\section{Uvea}

The uveal inflammatory reaction observed in 21 cases (66\%) was the most frequent ophthalmic manifestation of HL. Three cases were predominantly anterior, 5 had vitritis (Fig. 2), 13 presented with retinal or choroidal lesions (Fig. 3), and 7 presented with optic disc swelling (Table 3) [18-23]. Sixteen cases had bilateral involvement with asymmetric inflammation between both eyes, while the remaining 5 cases were unilateral. Cotton wool spot-like or hypopigmented chorioretinal lesions have been described in 8 cases [21,24-28]. In 4 patients with intraocular biopsies, either via fine-needle aspiration biopsy of an iris nodule, vitreous biopsy, enucleation, or via autopsy, ocular invasion by HL was not detected in any of the specimens.

\section{Retina}

Two cases showed a frosted branch angiitis pattern that resolved after chemotherapy (for HL disease) and oral corticosteroids (for ocular inflammation) (Table 4) $[29,30]$. One case by Barr et al. [19] was described as a bilateral periphlebitis with vitritis and swelling of the optic nerve. All cases with predominantly vascular inflammation were bilateral (Fig. 4). 
Table 3. HL: uveal manifestations

\begin{tabular}{|c|c|c|c|c|c|c|c|}
\hline Author & $\begin{array}{l}\text { Age, } \\
\text { sex }\end{array}$ & Eye & Initial VA & Signs & Initial diagnosis & Biopsy & $\begin{array}{l}\text { Diagnosis of } \\
\mathrm{HL}\end{array}$ \\
\hline Kamellin [24] & $26, M$ & OU & $\mathrm{CF}$ & $\begin{array}{l}\text { Macular retinitis with peripheral } \\
\text { white deposits }\end{array}$ & $\mathrm{N} / \mathrm{A}$ & Lymph node & Subsequent \\
\hline \multirow[t]{4}{*}{ Huggert [18] } & $53, \mathrm{M}$ & $\mathrm{OU}$ & $\mathrm{N} / \mathrm{A}$ & Iritis & $\mathrm{N} / \mathrm{A}$ & N/A & $\mathrm{N} / \mathrm{A}$ \\
\hline & $20, F$ & OU & $\mathrm{N} / \mathrm{A}$ & Iritis, vitritis & $\mathrm{N} / \mathrm{A}$ & $\mathrm{N} / \mathrm{A}$ & $\mathrm{N} / \mathrm{A}$ \\
\hline & $53, F$ & OU & $\mathrm{N} / \mathrm{A}$ & Uveitis + disc edema & $\mathrm{N} / \mathrm{A}$ & $\mathrm{N} / \mathrm{A}$ & N/A \\
\hline & $26, M$ & $\mathrm{OU}$ & $\mathrm{N} / \mathrm{A}$ & Choroiditis + disc edema & $\mathrm{N} / \mathrm{A}$ & $\mathrm{N} / \mathrm{A}$ & $\mathrm{N} / \mathrm{A}$ \\
\hline $\begin{array}{l}\text { Brihaye-Van } \\
\text { Geertruyden [25] }\end{array}$ & $31, F$ & $\mathrm{OU}$ & $20 / 20$ & Cotton wool spots & $\mathrm{N} / \mathrm{A}$ & $\begin{array}{l}\text { Lymph node + enucleation. } \\
\text { No infiltration of tumor cells in } \\
\text { the eye, cytoid bodies }\end{array}$ & Prior \\
\hline $\begin{array}{l}\text { Bishop and } \\
\text { Salmonsen [20] }\end{array}$ & $16, F$ & OD & Decreased & Retinal lesion & $\mathrm{N} / \mathrm{A}$ & $\mathrm{N} / \mathrm{A}$ & $\mathrm{N} / \mathrm{A}$ \\
\hline Kurz [26] & $31, F$ & OU & $\begin{array}{l}\text { Visual field } \\
\text { defect }\end{array}$ & Cotton wool spots & $\begin{array}{l}\text { Toxic effect of } \\
\text { polymixin } b\end{array}$ & $\begin{array}{l}\text { Widespread severe } \\
\text { degeneration of sensory } \\
\text { retina and RPE }\end{array}$ & \\
\hline $\begin{array}{l}\text { Barr and Joondeph } \\
\text { [16] }\end{array}$ & $28, F$ & $\mathrm{OU}$ & $\begin{array}{l}\text { OD: } 20 / 30 \text { OS: } \\
20 / 70\end{array}$ & $\begin{array}{l}\text { : Chorioretinitis, periphlebitis, disc } \\
\text { edema }\end{array}$ & N/A & Lymph node & Subsequent \\
\hline \multirow[t]{4}{*}{ Towler et al. [21] } & $25, M$ & $\mathrm{OU}$ & $20 / 40$ & $\begin{array}{l}\text { Small, discrete, pale choroidal } \\
\text { lesions }\end{array}$ & $\begin{array}{l}\text { Multifocal choroiditis } \\
\text { with vitritis }\end{array}$ & Lymph node & Subsequent \\
\hline & $22, F$ & OU & $20 / 30$ & $\begin{array}{l}\text { Iritis, vitritis, disc edema, } \\
\text { scattered white chorioretinal } \\
\text { lesions }\end{array}$ & Paraneoplasic uveitis & $\begin{array}{l}\text { FNAB without ocular invasion } \\
\text { of } \mathrm{HD}\end{array}$ & Subsequent \\
\hline & $71, M$ & $\mathrm{OU}$ & $20 / 60$ & $\begin{array}{l}\text { Vitritis, small hypopigmented } \\
\text { lesions in the posterior pole }\end{array}$ & Paraneoplasic uveitis & Lymph node & Prior \\
\hline & $24, \mathrm{M}$ & $\mathrm{OU}$ & $20 / 200$ & Iritis, vitritis, disc edema & VKH & Lymph node & Subsequent \\
\hline $\begin{array}{l}\text { Mateo-Montoya et } \\
\text { al. [27] }\end{array}$ & $29, F$ & $\mathrm{OU}$ & $20 / 100$ & $\begin{array}{l}\text { Vitritis, papillitis, white dots in } \\
\text { the outer retina }\end{array}$ & Paraneoplasic uveitis & Lymph node & Subsequent \\
\hline Mudhar et al. [22] & $71, F$ & OD & $\begin{array}{l}\text { OD: } 20 / 30 \text { OS: } \\
\text { 20/16 }\end{array}$ & $\begin{array}{l}\text { Iritis and vitritis (with snowballs } \\
\text { without pars planitis). No lesions } \\
\text { in retina }\end{array}$ & $\begin{array}{l}\text { Paraneoplasic } \\
\text { granulomatous } \\
\text { uveitis }\end{array}$ & $\begin{array}{l}\text { Vitreous: overall features were } \\
\text { those of a granulomatous } \\
\text { vitritis and retinitis. No } \\
\text { lymphoma }\end{array}$ & Subsequent \\
\hline Ohta et al. [28] & $58, M$ & $\mathrm{OU}$ & $\begin{array}{l}\text { OD: } 20 / 20 \\
\text { OS:20/30 }\end{array}$ & $\begin{array}{l}\text { Iritis and vitritis and } \\
\text { chorioretinitis }\end{array}$ & $\begin{array}{l}\text { Paraneoplasic } \\
\text { granulomatous } \\
\text { uveitis with retinal } \\
\text { involvement }\end{array}$ & Vitreous: no lymphoma & Prior \\
\hline Ayhan et al. [23] & $19, \mathrm{~F}$ & OS & $20 / 200$ & Iritis and vitritis & Uveitis & Lymph node & Subsequent \\
\hline
\end{tabular}

OD, right eye; OS, left eye; M, male; F, female; N/A, not applicable; HL, Hodgkin lymphoma; RPE, retinal pigment epithelium.

Table 4. HL: retinal manifestations

\begin{tabular}{|c|c|c|c|c|c|c|c|}
\hline Author & $\begin{array}{l}\text { Age, } \\
\text { sex }\end{array}$ & Eye & Initial VA & Signs & Initial diagnosis & Biopsy & $\begin{array}{l}\text { Diagnosis of } \\
\mathrm{HL}\end{array}$ \\
\hline Alhaj Moustafa et al. [30] & $71, F$ & OU & OD: $20 / 30$ OS: $20 / 50$ & $\begin{array}{l}\text { Frosted branch angitis } \\
\text { Choroidal neovascularization }\end{array}$ & $\begin{array}{l}\text { Paraneoplasic frosted branch } \\
\text { angiitis }\end{array}$ & Lymph node & Subsequent \\
\hline Hua et al. [29] & $22, \mathrm{M}$ & OU & $20 / 200$ & Frosted branch angitis & Idiopathic frosted branch angii & is Lymph node & Subsequent \\
\hline
\end{tabular}



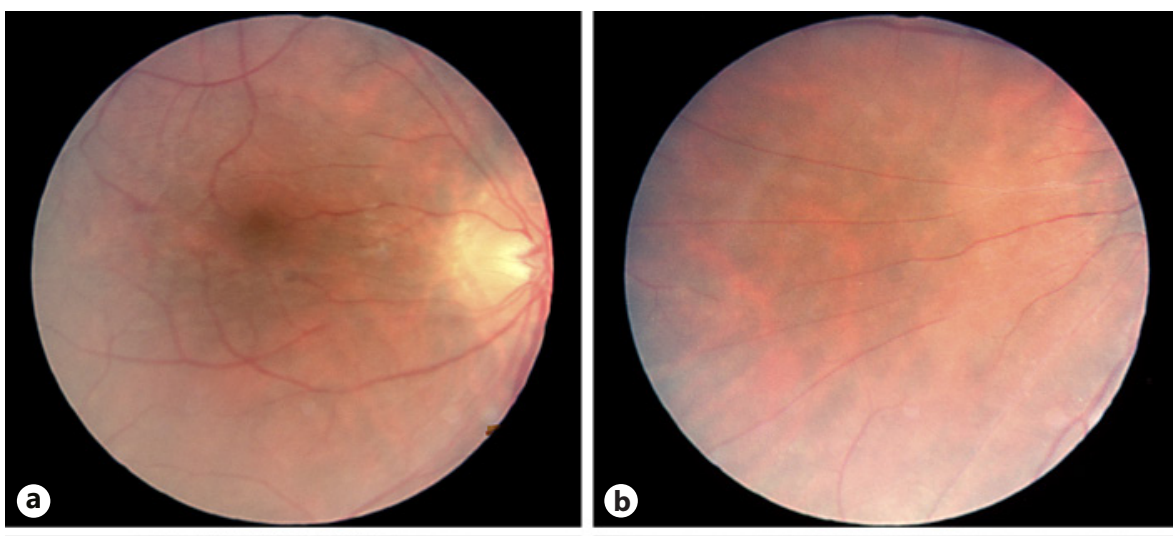

Fig. 4. A 23-year-old woman with history of HD in childhood presented with bilateral retinal vasculitis (fundus appearance right eye (a) and left eye (b). Note leakage on fluorescein angiogram (c, right eye and d, left eye). Over the years, she received numerous posterior sub-Tenon's injections of $40 \mathrm{mg}$ kenalog and fluocinolone acetonide intravitreal implant or Retisert ${ }^{\mathrm{TM}}$ in each eye for recurrent episodes of iritis, vitritis, retinal vasculitis, and cystoid macular edema. In the recent visit (10/2020), the last visit the best corrected vision was 20/40 in the right eye and 20/50 in the left eye. Secondary chorioretinal atrophic changes from previously treated vasculitis were noted (fundus appearance right eye (e) and left eye (f)).
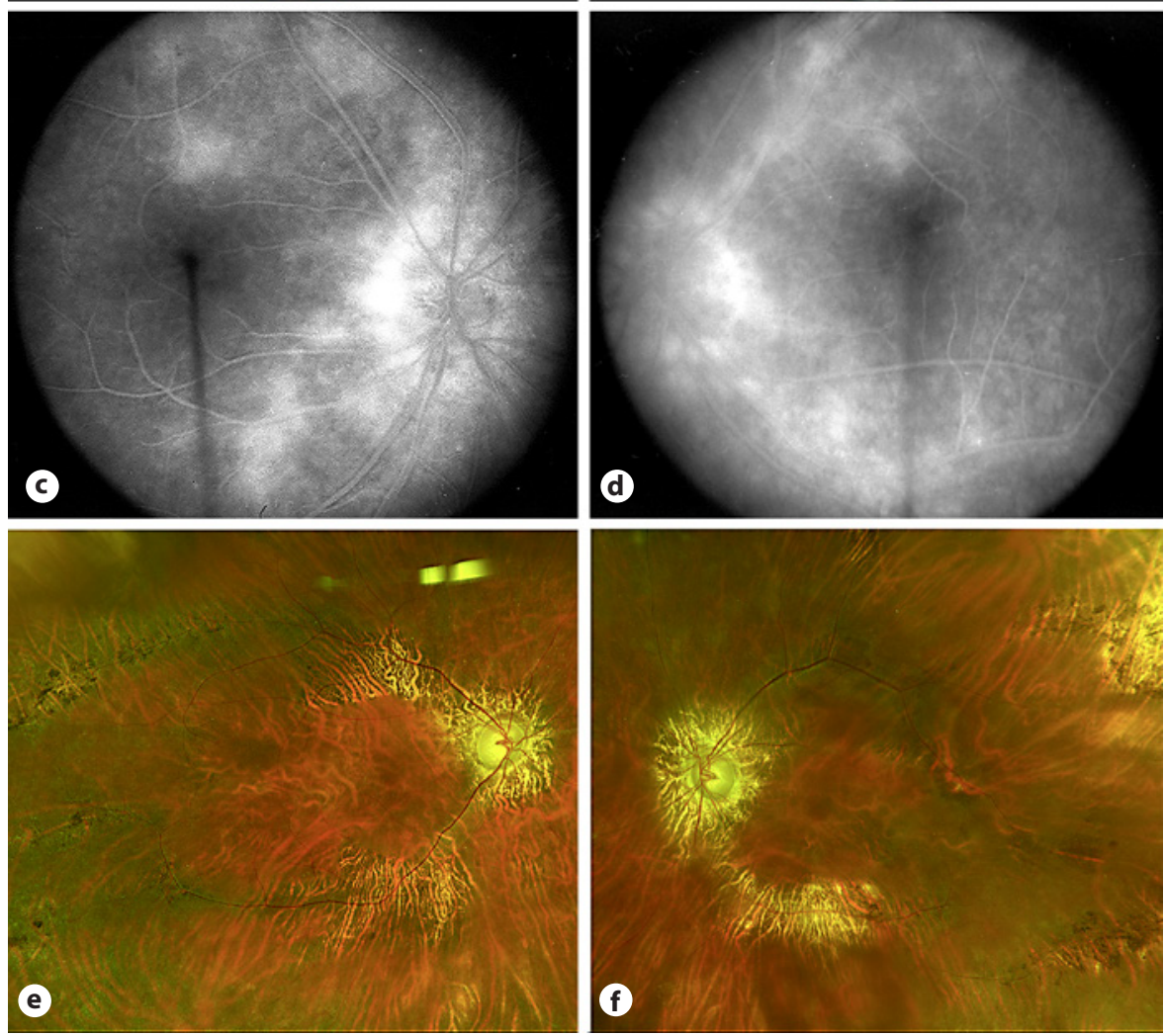

\section{Ophthalmic Manifestations: Paraneoplastic}

Only one case described as paraneoplastic retinopathy in HL has been reported by To et al. [31]. A 24-year-old woman with diagnosis of stage 3B HL was reported night blindness. Fundus examination revealed mild vitritis and diffuse retinal pigment epithelium atrophy. Serum testing revealed antibody binding the $65 \mathrm{kd}$ retinal protein. HL was treated with chemotherapy until remission was achieved. The retinal pigment epithelium atrophy was considered to be paraneoplastic. Despite treatment with oral corticosteroids, there was no improvement in visual acuity [31].

Ophthalmic Manifestations of Hodgkin Lymphoma

\section{Ophthalmic Manifestations: Toxic (Drug-Induced)}

Toxicity or adverse reaction to drugs used to treat $\mathrm{HL}$ may also contribute to ophthalmic involvement. Kurz et al. [26] reported a 31-year-old female with prior diagnosis of HL having soft, white cotton wool spot-like exudates throughout the retina and macular edema. The case was diagnosed as a secondary toxic reaction generated by the combined action of several drugs. The patient died from a secondary infection and the autopsy revealed complete atrophy of the sensory retina. Use of immune checkpoint inhibitors (CPI) in relapsing or refractory HL may be yet another mechanism of uveitis seen in patients with HL 
[32]. Temporal relationship between the onset of uveitis and onset of CPI agent may offer clues to the underlying etiology. Only one case has been reported with CPI-related uveitis in a patient with HL, which occurred at an estimated 380 days following initiation of treatment [33]. The case illustrated in this review is similar, except that ocular symptoms occurred 4 weeks after discontinuation of pembrolizumab (Fig. 2).

\section{Comment}

Ocular involvement in HL is extremely rare. Involvement can be classified into direct infiltration, inflammatory, paraneoplastic, or toxic (drug-induced). The distinction between inflammatory or paraneoplastic processes cannot be easily done in most cases.

Direct infiltration of the uvea and retina was not confirmed histopathologically in any of the reported cases. The only case with confirmed intraocular infiltration at autopsy revealed typical Reed-Sternberg cells in the anterior chamber and in the trabecular meshwork. There was no difference in presentation between this particular case and those with inflammatory manifestations.

The most common presentation is of uveitis without a characteristic pattern. Involvement could be exclusively anterior, intermediate, posterior, or panuveitis. All reported cases were classified to have granulomatous uveitis. The exact cause of this is uncertain but could be speculated to be related to the complex network of cytokines that shape the inflammatory microenvironment. Seven cases presented with optic disc swelling. Biopsy was performed in 4 cases. Mudhar et al. [22] presented a 71-yearold woman with a unilateral pan-uveitis. On vitreous biopsy, features of granulomatous vitritis and retinitis without the presence of tumoral cells were observed. Similar observations were made in all 4 cases, studied either by fine-needle aspiration biopsy or after enucleation [25]. Diagnosis was clinical in most cases, on the basis of temporal relationship and response to treatment. Biopsyproven intraocular invasion by tumor cells has been confirmed only in one case by Primbs et al. [14]. From the 21 cases diagnosed as uveitis, 7 were initially treated with either oral or intravenous corticosteroids. They had a partial response with improvement of ocular signs and symptoms but with recurrence when the treatment was suspended. Once the treatment with chemotherapy was initiated, all cases had either improvement or stabilization of the ocular signs and symptoms. White cotton wool like exudates were a common sign reported in these patients.
In 7 patients classified as inflammatory reaction, white choroidal or retinal dots were described. Brihaye-Van Geertruyden et al. [25] observed conglomerates of cytoid bodies on a histopathological study of these lesions, after autopsy on a patient diagnosed with HL and cotton wool like lesions. Three cases had been described with predominantly vascular inflammation such as retinal periphlebitis or frosted branch angiitis. All cases had good response to treatment: the first case reported by Barr et al. [19] was treated with RT, the second by Hua et al. [29] with oral corticosteroids for the ocular signs, and the third case by Ayhan et al. [23] with chemotherapy. Resolution of ocular signs was seen in all cases, and the percentage of visual acuity recovery correlated with the extent of evolution prior to diagnosis. Similarly, in 3 patients with corneal and conjunctival nodular lesions, histopathology revealed necrotizing granulomas rather than neoplastic infiltration [15-17].

\section{Conclusions}

Ocular involvement in HL is extremely rare. A few cases of histopathologically confirmed optic nerve/tract infiltration are within the spectrum of CNS involvement by HL. Importantly, the presence of Hodgkin/Reed-Sternberg-like cells alone is insufficient to establish a diagnosis of classic HL since these cells can occur in some types of non-HLs including peripheral T-cell lymphomas. Recognition of an inflammatory background typical of HL and separation from an underlying non-HL is key to making this distinction [34]. Inflammatory uveitis is the most common ophthalmic association of HL. Similar to presentation in non-HL, ophthalmic manifestations may precede diagnosis of HL. In the presence of prior known diagnosis of HL, restaging should be considered to exclude recurrence. Toxicity or adverse reaction to drugs used to treat HL may also contribute to ophthalmic involvement.

\section{Statement of Ethics}

Illustrative cases included in this review comply with the guidelines for human studies and was conducted ethically in accordance with the World Medical Association Declaration of Helsinki. Since this is a retrospective case series study without identification of the patient, informed consent from the patient was not required.

\section{Conflict of Interest Statement}

Juan Valenzuela had no relevant financial activities. Jose J. Echegaray was in the advisory board of Alimera Sciences. Emilio Dodds had no relevant financial activities. Shree K. Kurup had no
Ocul Oncol Pathol 2021;7:381-389 DOI: $10.1159 / 000519032$
Valenzuela/Echegaray/Dodds/Kurup/ Lowder/Ondrejka/Singh 
relevant financial activities. Careen Lowder had no relevant financial activities. Sarah L. Ondrejka had no relevant financial activities. Arun D. Singh was the Editor-in-Chief of Ocular Oncology and Pathology. He reported relevant financial activities outside the submitted work: Aura Biosciences (stock options); IsoAid LLC (consultancy); Immunocore (consultancy) Isoaid (consultancy), and Eckert and Zeigler (consultancy).

\section{Funding Sources}

This study did not receive any funding.

\section{Author Contributions}

All the authors contributed to writing and editing of the manuscript.

\section{Data Availability Statement}

All data generated and analyzed during this study are included in this article. Further inquiries can be directed to the corresponding author.

\section{References}

1 Shanbhag S, Ambinder RF. Hodgkin lymphoma: a review and update on recent progress. CA Cancer J Clin. 2018 Mar;68(2):116-32.

2 Harris NL. Hodgkin's disease: classification and differential diagnosis. Mod Pathol. 1999 Feb;12(2):159-75.

3 von Wasielewski R, Mengel M, Fischer R, Hansmann ML, Hübner K, Franklin J, et al. Classical Hodgkin's disease. Clinical impact of the immunophenotype. Am J Pathol. 1997 Oct;151(4):1123-30.

4 Kuppers R, Engert A, Hansmann ML. Hodgkin lymphoma. J Clin Invest. 2012 Oct; 122(10):3439-47.

5 Re D, Thomas RK, Behringer K, Diehl V. From Hodgkin disease to Hodgkin lymphoma: biologic insights and therapeutic potential. Blood. 2005 Jun 15;105(12):4553-60.

6 Townsend W, Linch D. Hodgkin's lymphoma in adults. Lancet. 2012 Sep 1;380(9844):83647.

7 Bonadonna G, Bonfante V, Viviani S, Di Russo A, Villani F, Valagussa P. ABVD plus subtotal nodal versus involved-field radiotherapy in early-stage Hodgkin's disease: long-term results. J Clin Oncol. 2004 Jul 15;22(14): 2835-41.

8 Bouliotis G, Bessell EM. Hodgkin disease (1973-2002): long-term survival and cure fractions. Leuk Lymphoma. 2015 May;56(5): 1278-85.

9 Miller NR, Iliff WJ. Visual loss as the initial symptom in Hodgkin disease. Arch Ophthalmol. 1975 Nov;93(11):1158-61.

10 Litvak J, Leder MM, Kauvar AJ. Hodgkin's disease involoving optic nerve and brain. J Neurosurg. 1964 Sep;21:798-801.

11 Siatkowski RM, Lam BL, Schatz NJ, Glaser JS, Byrne SF, Hughes JR. Optic neuropathy in Hodgkin's disease. Am J Ophthalmol. 1992 Nov 15;114(5):625-9.
12 Re D, Fuchs M, Schober T, Engert A, Diehl V. CNS involvement in Hodgkin's lymphoma. J Clin Oncol. 2007 Jul 20;25(21):3182.

13 Grimm S, Chamberlain M. Hodgkin's lymphoma: a review of neurologic complications. Adv Hematol. 2011;2011:624578.

14 Primbs GV, Monsees WE, Irvine AR Jr. Intraocular Hodgkin's disease. Arch Ophthalmol. 1961 Oct;66:477-82.

15 Barkana Y, Zadok D, Herbert M, Kornberg A, Nemet P. Granulomatous kerato-conjunctivitis as a manifestation of Hodgkin lymphoma. Am J Ophthalmol. 2001 Jun;131(6):7967.

16 Matteucci P. Corneal lesions in Hodgkin's disease; report of a case. Am J Ophthalmol. 1947 Feb;30(2):136-42.

17 Thakker MM, Perez VL, Moulin A, Cremers SL, Foster CS. Multifocal nodular episcleritis and scleritis with undiagnosed Hodgkin's lymphoma. Ophthalmology. 2003 May; 110(5):1057-60.

18 Huggert A. Uveitis in Hodgkin's disease. Acta Med Scand. 1955 Feb 23;151(2):155-9.

19 Barr CC, Joondeph HC. Retinal periphlebitis as the initial clinical finding in a patient with Hodgkin's disease. Retina. 1983;3(4):253-7.

20 Bishop JE, Salmonsen PC. Presumed intraocular Hodgkin's disease. Ann Ophthalmol. 1985 Sep;17(9):589-92.

21 Towler H, de la Fuente M, Lightman S. Posterior uveitis in Hodgkin's disease. Aust N Z J Ophthalmol. 1999 Oct;27(5):326-30.

22 Mudhar HS, Fernando M, Sheard R, Rennie I. Paraneoplastic granulomatous vitritis and retinitis as a presentation of recurrent classical Hodgkin's lymphoma. Int Ophthalmol. 2010 Aug;30(4):341-3.

23 Ayhan Z, Yıldırım Karabağ R, Alacacıŏlu İ, Kaynak S, Koçak N. Rare clinical sign of Hodgkin's lymphoma: ocular involvement. Turk J Ophthalmol. 2017 Apr;47(2):110-2.

24 Kamellin S. Uveitis associated with Hodgkin's disease: report of a case. Arch Ophthalmol. 1944;31(6):517-9.
25 Brihaye-Van Geertruyden M. Retinal lesions in Hodgkin's disease. AMA Arch Ophthalmol. 1956 Jul;56(1):94-9.

26 Kurz GH. Retinopathy of obscure (toxic?) origin in Hodgkin's disease. Am J Ophthalmol. 1964 Feb;57:205-13.

27 Mateo-Montoya A, Bonnel S, Wolff B, Héron E, Sahel JA. White dots in the eye fundus revealing Hodgkin's lymphoma. Eye. 2010 May; 24(5):934-7.

28 Ohta K, Yoshida A, Sato A, Fukui E, Kikuchi $\mathrm{T}$. Retinal involvement in uveitis associated with Hodgkin disease. Retin Cases Brief Rep. 2014 Winter;8(1):17-20.

29 Hua MT, Blaise P, De Leval L, Rakic JM. Frosted branch angiitis with undiagnosed Hodgkin lymphoma. Eur J Ophthalmol. 2009 Mar-Apr;19(2):310-3.

30 Alhaj Moustafa M, Crowell EL, Elmahdy S, Malkovska V, Reddy AK. Paraneoplastic frosted branch angiitis as first sign of relapsed Hodgkin lymphoma. Clin Case Rep. 2018 Oct;6(10):1978-81

31 To KW, Thirkill CE, Jakobiec FA, Lessell S, Berson EL. Lymphoma-associated retinopathy. Ophthalmology. 2002 Nov; 109(11): 2149-53.

32 Meti N, Esfahani K, Johnson NA. The role of immune checkpoint inhibitors in classical Hodgkin lymphoma. Cancers. 2018 Jun 15; 10(6).

33 Sun MM, Levinson RD, Filipowicz A, Anesi S, Kaplan HJ, Wang W, et al. Uveitis in patients treated with CTLA-4 and PD-1 checkpoint blockade inhibition. Ocul Immunol Inflamm. 2020;28(2):217-27

34 Eladl AE, Satou A, Elsayed AA, Suzuki Y, Kato S, Asano N, et al. Clinicopathological Study of 30 cases of peripheral T-cell lymphoma with Hodgkin and Reed-Sternberg-like Bcells from Japan. Am J Surg Pathol. 2017 Apr; 41(4):506-16. 